\title{
SHRINKAGE CRACKING OF THIN IRREGULAR SHOTCRETE SHELLS USING MULTIPHYSICS MODELS
}

\author{
ANDREAS SJÖLANDER*, TOBIAS GASCH ${ }^{\dagger}$, ANDERS ANSELL ${ }^{\dagger \dagger}$ AND RICHARD \\ MALM ${ }^{\dagger \dagger}$
} \author{
Stockholm, Sweden \\ * email: andreas.sjolander@byv.kth.se \\ $\dagger$ email: tobias.gasch@byv.kth.se \\ †† email: anders.ansell@byv.kth.se \\ †† email: richard.malm@byv.kth.se
}

KTH Royal Institute of Technology, Department of Civil and Architectural Engineering

Key words: Cracking, Fibre Reinforced Shotcrete, Multi-physics, Shrinkage

\begin{abstract}
Shotcrete (sprayed concrete) is commonly used to support tunnels in good quality hard rock. Including a drainage system often results in end-restrained sections of shotcrete, which have created problems with shrinkage induced cracking. In this paper a multi-physical material model with coupled behaviour between thermal actions, moisture transportation and mechanical strain has been used to model and describe the complex behaviour and effects of shrinkage of such a structure. The model was first calibrated against a free shrinkage test and then used to simulate an experimental setup for testing of end-restrained shrinkage. The first results lead to a need of tuning of the parameters controlling the drying of the shotcrete to accurately describe the experimental results. This tuning could be an indication that the shrinkage behaviour differs between a restrained and an un-restrained sample. However, further research about possible changes in the pore structure as well as more detailed measurements of the early shrinkage behaviour is needed before any such conclusions can be drawn.
\end{abstract}

\section{INTRODUCTION}

Tunnels in good quality hard rock are normally supported with plain, unreinforced shotcrete (sprayed concrete), or a combination of fibre reinforced shotcrete, FRS, and rock bolts. The commonly used excavation method for hard rock, drill and blast, will naturally result in a shotcrete shell with highly varying thickness due to the irregular shape of the rock surface. For shotcrete that are not continuously bonded to the rock, problems related to shotcrete shrinkage cracking have been reported
[1, 2]. Shrinkage and strength development of shotcrete are complex processes, depending on factors such as the composition, of shotcrete variations in relative humidity and temperature and is also highly influenced by the creep behaviour. In this paper an attempt to improve the accuracy and reliability in modeling the effects of shrinkage is made by using a multi-physical material model as presented by Gasch et al. [3]. The model has coupled behaviour between thermal actions as well as moisture transportation, i.e., drying and wetting of the shotcrete, and 
time-dependent deformations. An experimental setup for end-restrained shotcrete slabs subjected to shrinkage, as tested by Bryne et al. [4], will be used for comparison with the numerical results.

\subsection{Shotcrete sprayed on soft drains}

For tunnels, leaking water may cause problems with deterioration of shotcrete and corrosion of steel fibres. For tunnels built in cold climates, the formation of ice can cause spalling of the already cracked shotcrete. To increase the technical life span, as well as limit the downtime of the tunnel due to maintenance work, a drainage system must therefore be installed. One example of such a solution is to cover water leading cracks with a system of synthetic drain mats that will transport the water to a drainage system. The drain mats are fixed to the rock surface with rock bolts and covered with shotcrete, see Figure 1. The shotcrete is only bonded to the rock surface at the end of each drain mat and this, in combination with the low stiffness of the mat, creates an end-restrained slab. Shotcrete sprayed on drains are therefore always reinforced with fibres, which commonly are of steel or glass. In-situ investigations [2, 5] as well as experimental [6, 7] and numerical results [8, 9] have shown that end-restrained shotcrete slabs are prone to shrinkage cracking. The strainsoftening behaviour of FRS leads to the formation of few cracks whose width usually exceeds the limits according to standards with respect to durability [10].

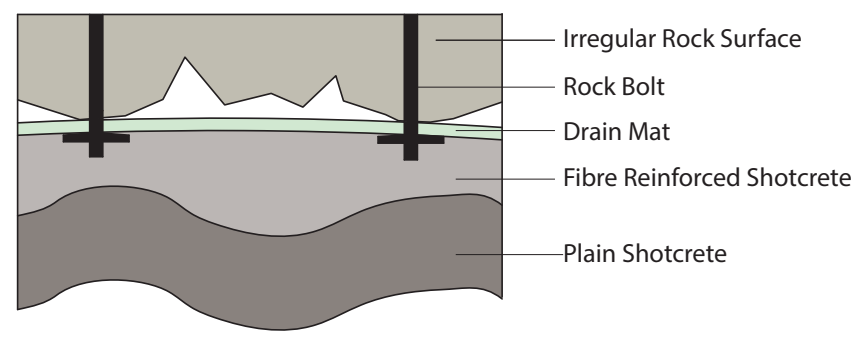

Figure 1: Build up of section with shotcrete sprayed on soft drains

\subsection{Shrinkage of shotcrete}

Autogenous and drying shrinkage of shotcrete are caused by chemical processes in the cement and evaporation of water. For shotcrete the fast development of bond strength and of internal ettringite crystals leads to shrinkage within a stiff structure. Movements in this structure will increase the porosity and therefore increase the rate of the drying shrinkage [11]. The use of shotcrete for rock support also implies that it will be loaded at an early stage due to the movement in the rock mass after excavation which further complicates the problem. This is, however, out of the scoop for this paper.

\subsection{Irregular thickness of shotcrete}

In-situ studies of the actual thickness of the applied shotcrete show that the standard deviation could be up to $50 \%$ of the intended thickness [2, 12]. Differences in applied thickness will mainly be due to problems with rebound, the quality of the substrate and skill of the operator [13]. If an end-restrained beam with irregular thickness is subjected to an evenly distributed tensile stress, the change in center of gravity along the beam will introduce effects of bending moment. An irregular geometric shape will also introduce local stress concentrations. Furthermore, the one sided drying condition of the shotcrete will introduce a strain gradient through the thickness. Since the rate of drying depends on the thickness a strain gradient will also exist in the plane of the thickness.

\section{BACKGROUND}

The material model used within this paper is based on the work by Gasch et al. [3] where a model with coupled behaviour between moisture, external heat and time-dependent deformation was presented. The model is based on the Microprestress-Solidification, MPS, theory as originally presented by Bazant et al. [14, 15, 16, 17] and later refined and improved by Jirsek and Havlsek [18]. The model has been implemented in the FE code Comsol Multiphysics [19] and is restricted to simulation of 
moisture transport under isothermal conditions, i.e., there is no coupling between moisture and thermal fields. The main concepts of the model are briefly described below and for a more thorough description the reader is refereed to given references.

\subsection{Moisture transport in concrete}

The physical mechanism of moisture exchange within a specimen and to its surrounding environment can be expressed with Fick's first law, which in its general form for two or more dimension can be written as in Eq. 1

$$
\mathbf{J}=-D_{h} \cdot \Delta \phi
$$

where $\mathbf{J}$ is the flux, i.e. the change in moisture content over the area, $D_{h}$ is the diffusivity of the concrete and the difference in relative humidity, $\Delta \phi$, is the driving force of the diffusion. The diffusivity describes the rate of change in relative humidity and is here described as a nonlinear function of the relative humidity. This equation was first presented in [20] and is now also recognized in the FiB Model Code [21]. For a relative humidity of $0 \leq \mathrm{H} \leq 1$ this equation can be simplified to Eq. 2

$$
D_{h}=-D_{1}\left[\alpha_{0}+\frac{1-\alpha_{0}}{1+\left({\frac{1-H}{1-H_{c}}}^{n}\right)}\right]
$$

The diffusivity is described by $D_{1}$ for $H=1.0$ and with $D_{1} \cdot \alpha_{0}$ when $H=0$. At a relative humidity equal to $H_{c}$ the rate of diffusion rapidly change with a magnitude described by the parameter $n$. The diffusivity is plotted in Figure 2.

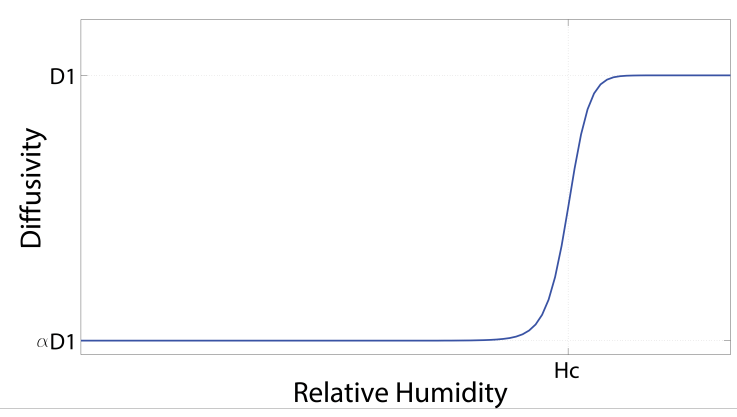

Figure 2: Relationship between diffusivity and relative humidity
Fick's first law describes the change in relative humidity during steady state. A transient event, such as drying of a concrete specimen, can be described with Fick's second law, as:

$$
\frac{\partial H}{\partial t}=D_{h} \nabla \phi
$$

The change in relative humidity over time, $\partial H$ $/ \partial t$, is in Eq. 3 described by the second derivative of the relative humidity, $\nabla \phi$ multiplied with the diffusivity. The moisture exchange between the specimen and the ambient air is described with a mixture of natural and essential boundary conditions described by Eq. 4

$$
-\mathbf{J} \cdot \mathbf{n}=\beta_{h} \cdot\left(H-H_{e n v}\right)
$$

Here $\mathbf{n}$ is the normal to the surface, where $\beta_{h}$ describe the rate of exchange in moisture between the surface and the ambient air which have a relative humidity equal to $H_{e n v}$. Finally, the relation between relative humidity within the shotcrete and its shrinkage is described by a single parameter, $k_{s h}$, which is determined by fitting experimental results to the numerical model.

\subsection{Damage model}

The effective stresses are described by an isotropic continuum damage model, based on the work by Oliver et. al [22]. Here the effective stress tensor, $\sigma$, is calculated based on the single damage scalar, $\omega$.

$$
\sigma=(1-\omega) D_{i}: \varepsilon^{i}
$$

In Eq. 5, $D_{i}$ and $\varepsilon^{i}$ are the elastic stiffness and strain tensors, respectively. The evolution of damage is here described by an exponential law in which the softening depends on the tensile strength and fracture energy.

\subsection{Experimentally work}

In a recent project carried out at the KTH Royal Institute of Technology focus was put on development of material parameters of shotcrete as well as the bond between young shotcrete and hard rock [23]. In addition to 
this, an experimental setup for testing of endrestrained shrinkage, see Figure 3, was developed and presented by Bryne et al. [4, 7]. The aim with this experiment was to simulate the shrinkage behaviour of shotcrete sprayed on soft drains. A granite slab with dimensions 1100x400x100 $\mathrm{mm}^{3}$ was used as a substrate and two layers of plastic film was placed to create a de-bonded area of $700 \times 400 \mathrm{~mm}^{2}$ for the shotcrete, simulating the effect of the drain mats. Shotcrete was then sprayed over the granite slab with a target thickness of $20 \mathrm{~mm}$. At the centre of the granite slab two strain gauges were placed $10 \mathrm{~mm}$ from the top and bottom, respectively. The restrained movement of the shotcrete slab could thus be monitored through the strains in the granite slab. The slabs were then placed in a climate chamber with $T=20$ ${ }^{\circ} \mathrm{C}$ and $R H=50 \%$. To reduce early drying shrinkage the slab was kept under a wet jute cloth covered by a thin plastic sheet for the first three days. At day four, the plastic sheet and jute cloth were removed and the measurements started. Thereby, early movement due to autogenous and drying shrinkage as well as thermal actions due to cement hydration was, unfortunately, not monitored. A hypothesis for the experiment was that the addition of glass fibres in the shotcrete could delay or prevent cracking. The experiment resulted in five cracked slabs and one failure due to de-bonding. Four of the slabs cracked after 6-7 days and one after 16 days. The time of failure was measured from the time of spraying. In Table 1 the composition of the shotcrete is presented.

Table 1: Composition of shotcrete [4]

\begin{tabular}{l|c} 
Material & Content $\left[\mathbf{k g} / \mathbf{m}^{3}\right]$ \\
\hline Cement & 495 \\
Densified silica & 19.8 \\
Water & 220 \\
Superplasticiser & 3.5 \\
Glass fibre & $0 / 5$ \\
Aggregate 0-2 mm & 394 \\
Aggregate 0-8 mm & 1183 \\
\hline
\end{tabular}

\section{NUMERICAL SIMULATIONS}

For the numerical simulations, results from two of the six slabs were used. Measurements of the actual thickness of the applied shotcrete were used to create accurate geometric models. The measured $\mathrm{min} / \mathrm{max} / \mathrm{mean}$ thickness of slab 1 and 2 was 12/38/25 $\mathrm{mm}$ and 25/45/37 mm, respectively. For slab 1 plain shotcrete was used while slab 2 was reinforced with $5 \mathrm{~kg} / \mathrm{m}^{3}$ of glass fibres. The two slabs were chosen due to their differences in time at failure; slab 1 failed after 6 days and slab 2 after 16 days. The difference is believed too partly be related to the geometry and it is therefore interesting to investigate if the numerical simulations can capture this behaviour.
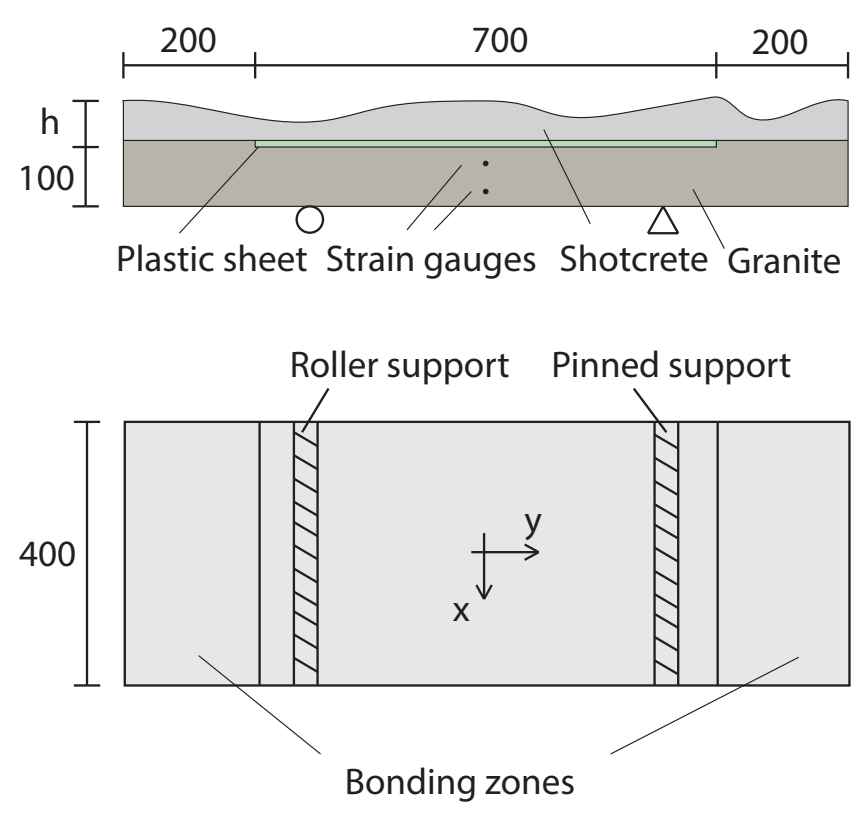

Figure 3: Experimental set-up for end-restrained shrinkage test from Bryne et. al [4]

Shrinkage was applied in two different ways in the models to investigate the effects, and possible importance, of non-linear shrinkage. First, the measured free shrinkage after 50 days, see 3.3 , was recalculated to an equivalent temperature load according to Eq. 6.

$$
T_{e q}=\frac{\varepsilon_{s h}}{\alpha}
$$

Here $\alpha$ is the coefficient of thermal expansion for shotcrete, see Table 2. With a free shrinkage, $\varepsilon_{s h}$ of $-360 \mu \varepsilon$ the equivalent temperature 
Table 2: Mechanical properties of granite and shotcrete

\begin{tabular}{l|ccl} 
Parameter & Value & Unit & Comment \\
\hline $\mathrm{E}_{g}$ & 70 & $\mathrm{GPa}$ & Young's modulus of granite \\
$\nu_{g}$ & 0.2 & - & Poisson's ratio of granite \\
$\rho_{g}$ & 2600 & $\mathrm{~kg} / \mathrm{m}^{3}$ & Density of granite \\
\hline $\mathrm{E}_{c 0}$ & $38(38)$ & $\mathrm{GPa}$ & Young's modulus of plain shotcrete at 28 days \\
$\nu$ & 0.2 & - & Poisson's ratio of shotcrete \\
$\rho_{g}$ & 2300 & $\mathrm{~kg} / \mathrm{m}^{3}$ & Density of shotcrete \\
$\mathrm{f}_{c k 0}$ & $61(59)$ & $\mathrm{MPa}$ & Compressive strength plain shotcrete at 28 days \\
$\mathrm{f}_{c t m 0}$ & $4.4(4.3)$ & $\mathrm{MPa}$ & Tensile strength of plain shotcrete at 28 days \\
$\mathrm{G}_{f}$ & $153(152)$ & $\mathrm{Nm}$ & Fracture energy of plain shotcrete at 28 days \\
\hline $\mathrm{sf}$ & 0.575 & $\mathrm{~mm} / \mathrm{d}$ & Moisture surface factor \\
$\mathrm{ksh}$ & 0.001 & - & Shrinkage related to relative humidity \\
$\mathrm{D}_{1}$ & $1.9 * 10^{-10}$ & $\mathrm{~m} 2 / \mathrm{s}$ & Diffusivity of shotcrete at H=1.0 \\
$\mathrm{H}$ & 0.80 & - & Relative humidity \\
$\alpha_{0}$ & 0.05 & - & Relation between diffusivity at H=1.0 and $\mathrm{H}=0$ \\
$\mathrm{n}$ & 15 & - & Describing rate of change in diffusivity at $\mathrm{H}_{c}$ \\
\hline
\end{tabular}

become $-36^{\circ} \mathrm{C}$, the change in temperature was assumed linear over the time period of 50 days. Shrinkage was then simulated with the multiphysical model where the relative humidity of the shotcrete and ambient air was set to $100 \%$ and $50 \%$, respectively.

\subsection{Numerical model}

A 3D finite element model was created using a free tetrahedral mesh. To increase the accuracy in describing the irregular geometry and allow for a minimum of four elements through the thickness of the shotcrete slab the element size was set to $3-8 \mathrm{~mm}$. The geometry of the granite slab was considered to be perfectly flat and a linear elastic material model and an element size of 20-30 mm was used. The interaction between the shotcrete and granite slab at the bonding zone, see Fig 3, was modelled using a tie condition and hence de-bonding was not considered. Between the bonding zones, a contact surface was used between the two slabs. The contact in the xy-plane, see Figure 3, was friction less and separation was allowed due to tensile forces acting perpendicular to the xy-plane. Drying of the shotcrete slab was allowed along all free sides and the boundary conditions for the slab were modelled with a roller and pinned support, see Fig. 3. Rotation at the boundary conditions was allowed around the x-axis. The gravity load from shotcrete and granite was considered and each model resulted in a total of approximately $800.000 \mathrm{DOF}$. An attempt to include the effects of creep resulted in around 25 million DOF and due to limitations in time and computational power, creep was not considered.

\subsection{Mechanical properties}

The evolution of compressive strength for plain, $f_{c k 0}$, and glass fire reinforced (GFR), $f_{c k 5}$, shotcrete presented in Eq. 76 8 are based on the work presented in [7]. Tensile strength and fracture energy were not tested and estimations of Young's modulus based on flexural tests were believed to underestimate the stiffness. The mechanical properties of these parameters are, therefore, based on their relation to the compressive strength as given in Eurocode 2 and the FiB Model Code [21, 24].

$$
\begin{aligned}
& f_{c k 0}(t)=76.68 e^{-1.70 /(t)^{0.60}} \\
& f_{c k 05}(t)=81.41 e^{-1.86 /(t)^{0.53}}
\end{aligned}
$$

The added glass fibres had a length of $6 \mathrm{~mm}$ and based on regular four point bending test performed by [23] and presented by [9] it could 
be concluded that the increase of fracture energy was small and it was therefore omitted in these simulations. All mechanical properties of the granite and shotcrete are presented in Table 2 together with parameters used to describe the moisture transport in the shotcrete. Numbers within brackets are for $5 \mathrm{~kg} / \mathrm{m}^{3} \mathrm{GRF}$ shotcrete.

\subsection{Verification of free shrinkage}

Free shrinkage tests of plain and glass fibre reinforced shotcrete as well as a reference test with plain, un-reinforced, concrete is presented in [4]. The shotcrete was first sprayed into a box-shaped mould and left to cure under water for three days. After 24 hours the mould was removed and after 72 hours specimens with a dimension of $100 \times 100 \times 400 \mathrm{~mm}^{3}$ was sawn out. The specimens were then placed into a climate chamber with $T=20{ }^{\circ} \mathrm{C}$ and $R H=50 \%$ where drying was allowed along all sides. The free shrinkage of plain shotcrete is described by Eq. 9 which, due to uncertainties in the measurements of the young shotcrete, is valid for $7 \leq \mathrm{t} \leq 112$ days [4]. The deviation in the measured free shrinkage for plain and GFR shotcrete is negligible for the studied time of 20 days and the free shrinkage for plain shotcrete was therefore used.

$$
\varepsilon_{s h}=0.085 e^{-4.22 /(t-7)^{0.42}}
$$

In the plot of the free shrinkage in Figure 4 the numerical model, red solid line, shows good agreement with the test results, blue solid line. In an attempt to match the timeline for the restrained shrinkage tests, which started after three days of curing, measured values from day 4-7 were added. To match the experimental results, a ramp function was added to the boundary condition of the humidity, i.e., the external humidity was assumed to vary linearly from $R H=100 \%$ to $R H=50 \%$ during a period of 10 days. The slow initial shrinkage could be due to that the drying of the surface of the specimen took some time after the water curing process or the mentioned inaccuracy in the measurements. If the free shrinkage instead was assumed to start at day 7 , from which reliable measurements exist, the ramp function could be omitted and the resulting simulated free shrinkage is presented by the red dashed line in Figure 4. This model will be used for simulation of the end-restrained shrinkage.

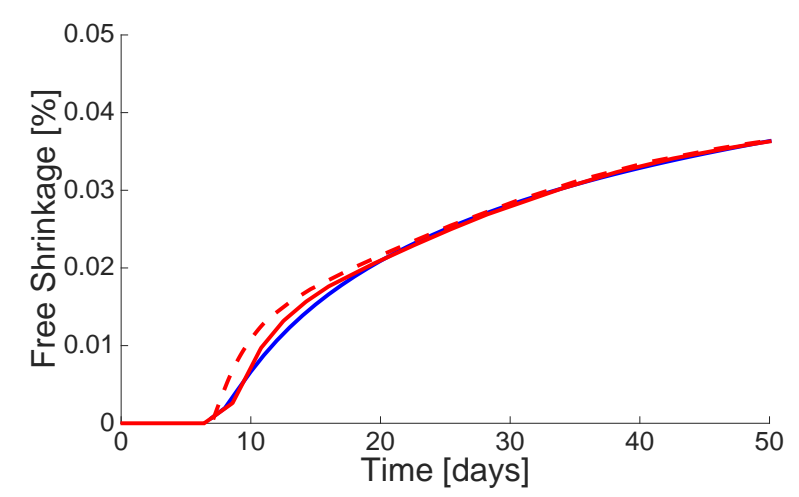

Figure 4: Free shrinkage of shotcrete from experiments and numerical simulations. Blue line is result from measurement and red lines are from numerical simulations. Red solid and dashed lines are with and without the ramp function starting at day four and seven, respectively.

\section{RESULTS}

In Figure 5 results from the numerical simulations of slab-1 and 2, respectively, are presented. The strains are presented at the location of the strain gauges, as previously shown in Figure 3, and plotted at the top of the figure. Dashed lines, in Figure 5, are the mean values from the experiment where strains were measured on both sides of the slab. Blue solid lines are results from the multi-physical model and red lines are results when shrinkage was applied as an equivalent temperature load. Due to the lack of early measurements, the initial strain in the granite slab, at $\mathrm{t}=3$ days, were estimated by assuming that the strains in the granite slab after cracking would be equal to zero. The bottom of the figure shows the location of cracks in the shotcrete, plotted on a contour plot that represents the thickness of the shotcrete. The thin black solid lines show the end of the bonding zones. As can be seen in top of Figure 5, the levels of strains show good correspondence between the experiments and the simulations, except for the results from the temperature model 

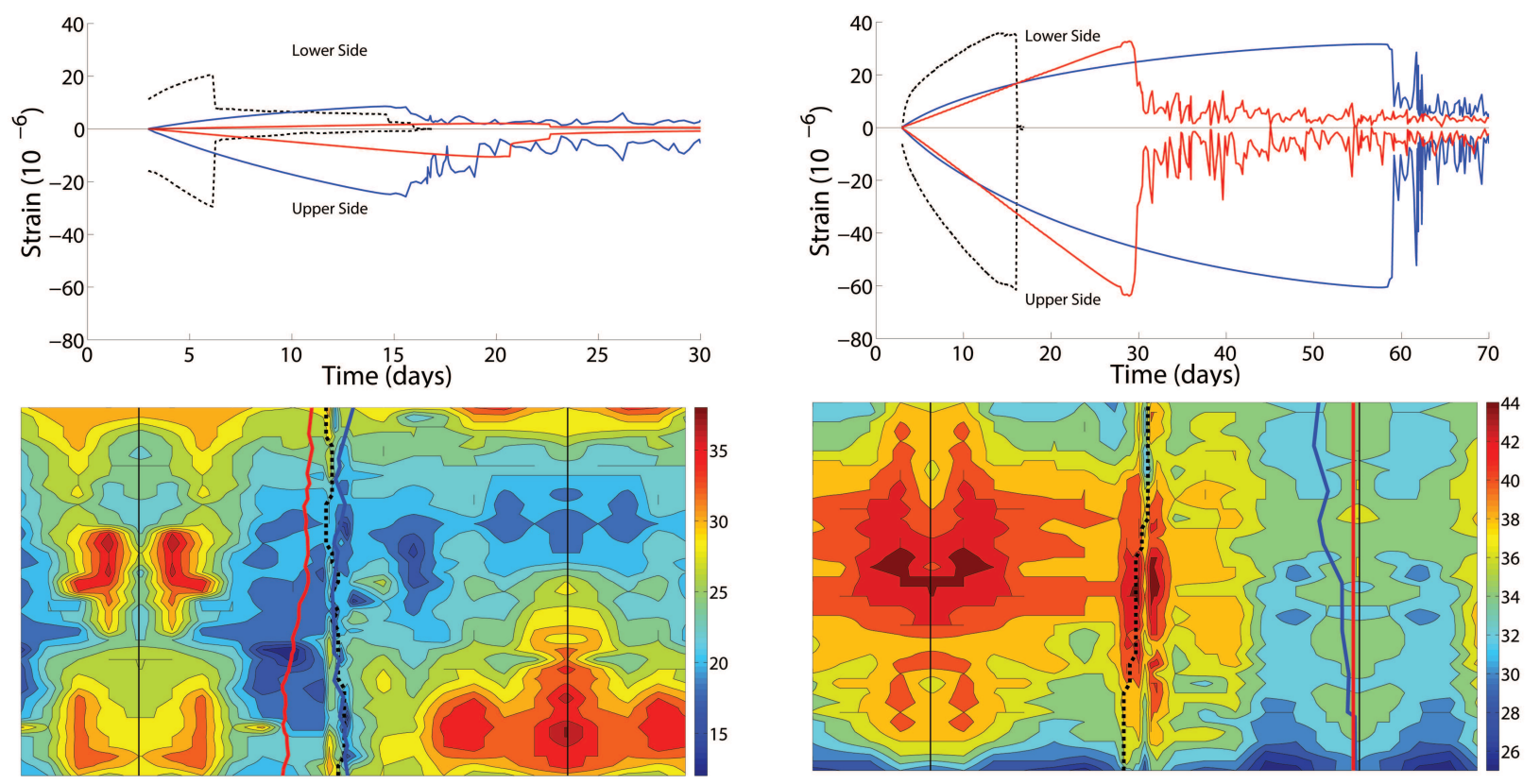

Figure 5: Results from experiment, dashed line, temperature model, red line, and multi-physical model, blue line, for slab-1 (left) and slab-2 (right). Top figure shows strain in the granite and bottom figure shows crack patterns plotted on a contour plot representing the thickness of the shotcrete slab.

for slab-1. This indicates that the mechanical properties of shotcrete and granite are quite accurate. The localization of the crack, as presented at the bottom of Figure 5, showed good agreement for slab-1 meanwhile it localized very close to the bonding zone for slab-2. The time of failure for the temperature model will depend on how the change in temperature was modelled and a linearly decreasing temperature over 50 days clearly underestimates the effects of early shrinkage. The fact that the failure in the multi-physical model occurs much later indicates that the shrinkage of the restrained slabs could not be accurately described by the results from the free shrinkage test.

\section{DISCUSSION}

The large difference in results could be due to several reasons and first the possible inaccuracy and errors in the measurements of the free shrinkage must be considered. The start of measurements at day four together with unreliable results until day seven makes it difficult to accurately predict the failure of slab1 , which occurred after six days. The slabs were water cured but not stored under water, as the specimens for the free shrinkage test. This would likely have resulted in faster initial drying shrinkage of the slabs since these were not fully saturated at the start of the drying process. This was, as described previously, accounted for by excluding the ramp function used for the boundary conditions. This is indicated by the red dashed curve in Figure 4. Even though this slow initiation of the drying process was omitted in the numerical analysis, the time of failure was around three times higher than the experiments. The positive stress-relieving effects of creep, which had to be omitted in the model, should have further increased the difference in time. However, to better match the experimental results two approaches were undertaken. The first one was based on adjusting the parameters controlling the moisture transportation and for the second one, an initial state of stress in the shotcrete was assumed at the start of the drying process. 


\subsection{Tuning of the moisture transportation model}

To tune the moisture transportation model the diffusivity, $D_{1}$, was first increased which speed up the moisture transportation within the shotcrete. When shrinkage occurs in the stiff shotcrete structure the porosity will change [11] which would increase the diffusivity. Since both the slabs and the test specimens for free shrinkage were shotcreted, this effect should be accounted for. The difference between the tests was thus that the slabs were end-restrained and it could be possible that this increased stiffness of the structure could further increase the porosity. The normal bond strength, during similar conditions as to the experimental setup, can according to Bryne et al. reach $1 \mathrm{MPa}$ within 24 hours [25]. However, further research must be conducted before any conclusion could be drawn. It should be added that the model does not account for an increased moisture transportation through the cracks which could have an effect on the results. Secondly, the surface factor, $s f$, was increased which control the rate of exchange in relative humidity between the surface of the shotcrete and the ambient air. This increase the rate of change in relative humidity, which is the driving force of the diffusion, between the surface and the inside of the shotcrete slab. Both the free shrinkage test and end-restrained test were performed within a climate chamber. The environmental conditions were therefore controlled and the increased surface factor could be explained by the shotcrete slab not being fully saturated at the start of drying. To fit the experimental results both $D_{h}$ and $s f$ had to be increased with a factor of four. The strains at the location for the strain gauge, see Figure 3, are plotted in Figure 6 where solid and dashed lines represent numerical and experimental results, respectively. Even though an increase of both the parameters can be justified physically, a factor of four feels rather large. However, the tuned moisture model captures the rate of strain and the time of failure of the experiment very well.

\subsection{Initial state of stress}

Due to autogenous shrinkage and thermal effects of the hydrated cement it is reasonable to assume an initial state of stress in the shotcrete at the start of monitoring, i.e., at $\mathrm{t}=3$ days. Estimations of the initial strains in the granite slab were, as previously described, performed by [23]. Strains for the six slabs were estimated to be between $0-10 \mu \varepsilon$ and $0-(-20) \mu \varepsilon$ for the lower and upper strain gauge, respectively. These assumed initial strains corresponds rather well to measured strains presented by [7]. However, in that test cast shotcrete slabs were used, i.e., concrete with properties of sprayed concrete, and the environmental conditions were not controlled. A uniform distributed temperature load of $-7{ }^{\circ} \mathrm{C}$ and $-3.5^{\circ} \mathrm{C}$ was applied to shotcrete slab-1 and 2 to generate an initial stress in the shotcrete, as well as an initial strain the granite. In Figure 7 the strains from the experiment and the numerical analysis are plotted. Dashed and solid lines are from experiments and numerical analysis, respectively. The applied initial strains for slab-1, blue lines in Figure 7, corresponds well to estimated strains but was overestimated for slab-2, red lines in Figure 7. The time of failure and the rate of strains were underestimated for both slabs. This indicates that the rate of strain described by the model must be changed to accurately describe the experiment. A combination of an initial stress and a tuned moisture transportation model could most likely be used to more accurately simulate the experiment.

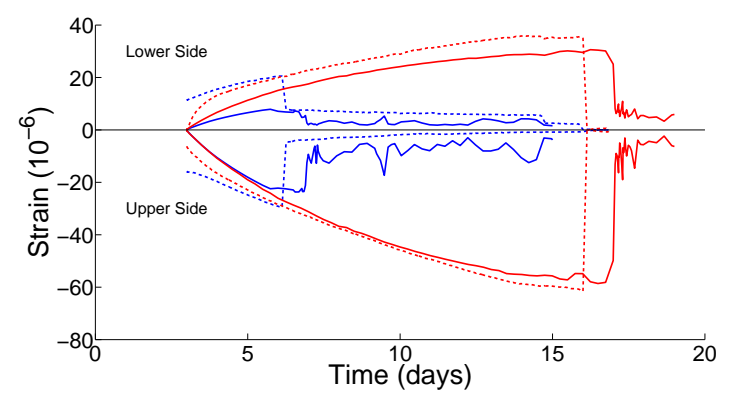

Figure 6: Strains in granite slab from experiments, dashed lines, and simulations, solid lines. Blue line is for slab 1 and red line for slab 2. Parameters controlling the moisture transportation have been tuned. 


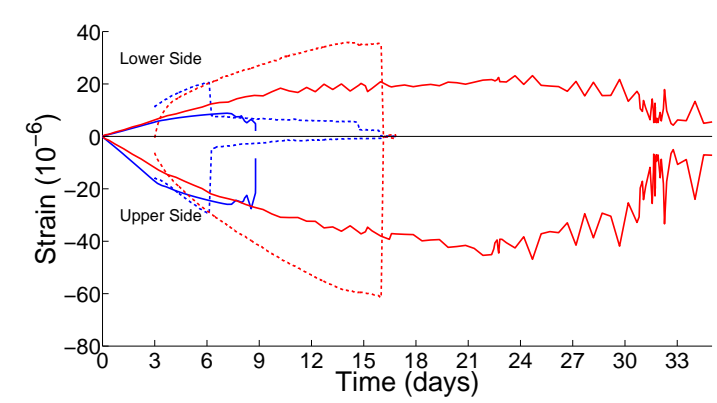

Figure 7: Strains in granite slab from experiments, dashed lines, and simulations, solid lines. Blue line is for slab 1 and red line for slab 2. An initial state of stress at $\mathrm{t}=3$ days have been assumed.

\subsection{Temperature model}

The temperature model can as well be finetuned to accurately describe the time of failure of the shotcrete slab, by simply changing the time over which the temperature decreases. By using an exponential decreasing function the effects of early shrinkage can also be accounted for. However, the temperature model is limited to simulate shrinkage with the same constant relative humidity as the test it has been verified against. Since shrinkage in the multi-physical model is rather described by the physical process of drying, it can also be used for simulations with different environmental conditions.

\subsection{Damage model}

The results have shown some non-unique solutions with respect to crack patterns, which further influence the levels of strain and time of failure. This can be seen by comparing the simulated levels of strain at failure for slab-2, presented in Figure 6and 7. The damaged areas in the slabs are similar for different analysis, but the localization of the final crack varies. The irregular geometry introduces effects of bending moment in the slabs and damage will therefore develop in thinner sections first. Damage will then either propagate in this section, or start to form in other thin sections. This enables the formation of damage in several small areas of the slab before the final crack is localized. This is believed to be the reasons for the variation of crack localization.

\section{CONCLUSIONS}

In this paper a coupled multi-physical material model has been used in an attempt to simulate experimental results for an end-restrained shotcrete slab subjected to shrinkage. A free shrinkage test was used to tune the moisture transportation model which was then used to simulate the experiment. First results lead to a need of tuning of the model which, possibly, is a combined effect of an initial state of stress in the shotcrete and an increased rate of strain.

The presented results indicate that for future studies, more detailed measurements are needed. To enable the moisture transportation model to be more accurately tuned, temperature and relative humidity within the shotcrete should be measured. Measurements should start as soon as possible after spraying to capture the effects of autogenous shrinkage and thermal effects due to the hydration of cement. The presence of cracks will locally increase the moisture transportation and their occurrence should therefore be more thoroughly monitored during the experiment. Future studies should also focus on whether or not a restrained sample will shrink faster compared to an unrestrained sample. Such a study should also include the structure of the material, i.e., the porosity.

It can be concluded that both types of models, the multi-physical and the uncoupled, can be tuned to accurately simulate the experimental results. However, besides being a more physical correct solution to the shrinkage problem the multi-physical model will also be able to simulate the behaviour with various boundary conditions, i.e., different relative humidity. The multi-physical model is therefore preferable but some further improvements are needed. Because shrinkage cracks in the experiment occurred within 16 days, the multi-physical model must, clearly, be improved to also account for development of thermal stresses due to the hydration of cement as well as autogenous shrinkage. The effects of cracks with respect to moisture transportation should also be added. Finally, it would be desirable to increase the robustness of the damage model in terms of local- 
ization of the cracks.

\section{ACKNOWLEDGEMENTS}

The work presented in this paper is part of a larger research project focusing on numerical simulations of irregular shotcrete and the interaction between shotcrete and rock. The project is sponsored by BeFo, the Rock Engineering Research Foundation and their support is hereby greatly acknowledged.

\section{References}

[1] Holmgren J B. Shotcrete research and practice in Sweden a development over 35 years. In: Shotcrete: Elements of a system. TSE Pty. Ltd. Sydney Australia: CRC Press/Balkema; 2010. p. 135-142.

[2] Ansell A. Investigation of shrinkage cracking in shotcrete on tunnel drains. Tunnelling and Underground Space Technology. 2010 sep;25(5):607-613.

[3] Gasch T, Malm R, Ansell A. Modelling time-dependent deformations of concrete subjected to variable environmental conditions using a coupled hygro-thermomechanical model. To be published. 2015;

[4] Bryne E L, Holmgren J, Ansell A. Shrinkage testing of end-restrained shotcrete on granite slabs. Magazine of Concrete Research. 2014;p. 1-11.

[5] Malmgren L, Nordlund E, Rolund S. Adhesion strength and shrinkage of shotcrete. Tunnelling and Underground Space Technology. 2005;20(1):33-48.

[6] Carlswärd J. Shrinkage cracking of steel fibre reinforced self compacting concrete overlays Test methods and theoretical modelling; 2006.

[7] Bryne E L, Ansell A, Holmgren J. Investigation of restrained shrinkage cracking in partially fixed shotcrete linings. Tunnelling and Underground Space Technology. 2014 may;42:136-143.
[8] Groth P. Fibre Reinforced Concrete. Luleå University of Technology; 2010.

[9] Sjölander A, Ansell A, Bryne E L. Numerical simulations of restrained shrinkage cracking of shotcrete. To be published. 2015;

[10] Holmgren J, Ansell A. Test on restrained shrinkage of shotcrete with steel fibres and glas fibres. In: Federation NC, editor. Proceedings of the XX Symposium on Nordic Concrete Research; 2008. .

[11] Lagerblad B, Fjällberg L, Vogt C. Shrinkage and durability of shotcrete. In: Shotcrete: Elements of a system. TSE Pty. Ltd. Sydney Australia: CRC Press/Balkema; 2010. p. 173-180.

[12] Malmgren L, Nordlund E. Interaction of shotcrete with rock and rock bolts A numerical study. International Journal of Rock Mechanics and Mining Sciences. 2008 jun;45(4):538-553.

[13] Brekke L T, Einstein H H, Mason E R. State-of-the-art review on shotcrete [Final report]; 1976.

[14] Bažant P Z, Prasannan S. Solidification theory for concrete creep. I: Formulation. Journal of Engineering Mechanics. 1989;115(8):1691-1703.

[15] Bažant Z, Prasannan S. Solidification theory for concrete creep. II: Verification and Application. Journal of Engineering Mechanics. 1989;115(8):1704-1725.

[16] Bazant Z, Hauggaard A, Baweja S, Ulm F. Microprestress-solidification theory for concrete creep 1: Aging and drying effects. Journal Of Engineering Mechanics. 1997;123(11):1188-1194.

[17] Bazant P Z, Hauggaard B A, Baweja $S$. Microprestress-solidification theory for concrete creep 2: Algorithm and verification. Journal Of Engineering Mechanics. 1997;123(11):1195-1201. 
[18] Jirásek M, Havlásek P. Microprestresssolidification theory of concrete creep: Reformulation and improvement. Cement and Concrete Research. 2014;60:51-62.

[19] COMSOL. COMSOL, Multiphysics ver 5.1 Documentation; 2015.

[20] Bažant P Z, Najjar J L. Nonlinear water diffusion in nonsaturated concrete. Matriaux et Construction. 1972;(1):3-20.

[21] fib. fib Model Code for Concrete Strucutres. Wiley-VCH Verlag GmbH Co; 2010.

[22] Oliver J, Cervera M, Oller S, Lubliner J. Oliver-1990-Isotropic damage models and smeare.pdf. Computer Adided Analysis and Design of Concrete Strucutres. 1990;p. 945-957.

[23] Bryne E L. Time Dependent Material Properties of Shotcrete for Hard Rock Tunneling; 2014.

[24] CEN. Eurocode 2: Design of Concrete Strucutre -Part 1-1: General rules and rules for buildings; 2004.

[25] Bryne E L, Ansell A, Holmgren J. Laboratory testing of early age bond strength of shotcrete on hard rock. Tunnelling and Underground Space Technology. 2014 mar;41:113-119. 